\title{
Identification of the anti-breast cancer targets of triterpenoids in Liquidambaris Fructus and the hints for its traditional applications
}

\author{
Ping Qian, Xiao-Ting Mu, Bing Su, Lu Gao and Dong-Fang Zhang*
}

\begin{abstract}
Background: Liquidambaris Fructus is the infructescences of Liquidambar formosana Hance and it has been used to treat some breast disease in Traditional Chinese Medicine. In the previous study we found the anti-breast cancer effect of triterpenoid in Liquidambaris Fructus. This study is a further investigation of the triterpenoids in Liquidambaris Fructus and aims to identify their anti-breast cancer targets, meanwhile, to estimate the rationality of the traditional applications of Liquidambaris Fructus.

Methods: Triterpenoids in Liquidambaris Fructus were isolated and their structures were identified by NMR spectrums. Potential targets of these triterpenoids were predicted using a reverse pharmacophore mapping strategy. Associations between these targets and the therapeutic targets of breast cancer were analyzed by constructing protein-protein interaction network, and targets played important roles in the network were identified using Molecular Complex Detection method. Binding affinity between the targets and triterpenoids was studied using molecular docking method. Gene ontology enrichment analysis was conducted to reveal the biological process and signaling pathways that the identified targets were involved in.

Results: Thirteen triterpenoids were identified and 6 of them were the first time isolated from Liquidambaris Fructus. Predicted ADME properties revealed a good druggability of these triterpenoids. We identified 18 protein targets which were closely related to breast cancer progression, especially triple-negative, basal-like or advanced stage breast cancers. The triterpenoids could bind with these targets as their inhibitors: hydrophobic skeleton is a favorable factor for them to stabilize at binding site and polar C17- or C3- substituent was necessary for binding. GO enrichment analysis indicated that inhibition of protein tyrosine kinases autophosphorylation might be the primary mechanism for the anti-breast cancer effect of the triterpenoids, and ErbB4 and EGFR were the most relevant targets.
\end{abstract}

Conclusions: The study revealed that triterpenoids from Liquidambaris Fructus might exert anti-breast cancer effect by directly inhibit multiple protein targets and signaling pathways, especially ErbB4 and EGFR and related pathways. This study also brings up another hint that the traditional applications of Liquidambaris Fructus on hypogalactia should be reassessed systematically because it might suppress rather than promote lactation by inhibiting the activity of ErbB4.

Keywords: Liquidambaris Fructus, Breast cancer, Triterpenoids, Network pharmacology, Molecular docking, ErbB4, EGFR

\footnotetext{
* Correspondence: dfzhang@cmu.edu.cn

Department of Pharmacognosy, School of Pharmacy, China Medical

University, Shenyang 110122, China
}

(c) The Author(s). 2020 Open Access This article is licensed under a Creative Commons Attribution 4.0 International License, which permits use, sharing, adaptation, distribution and reproduction in any medium or format, as long as you give appropriate credit to the original author(s) and the source, provide a link to the Creative Commons licence, and indicate if changes were made. The images or other third party material in this article are included in the article's Creative Commons licence, unless indicated otherwise in a credit line to the material. If material is not included in the article's Creative Commons licence and your intended use is not permitted by statutory regulation or exceeds the permitted use, you will need to obtain permission directly from the copyright holder. To view a copy of this licence, visit http://creativecommons.org/licenses/by/4.0/ The Creative Commons Public Domain Dedication waiver (http://creativecommons.org/publicdomain/zero/1.0/) applies to the data made available in this article, unless otherwise stated in a credit line to the data. 


\section{Background}

Liquidambaris Fructus (LF), also called Lu Lu Tong, is the dry infructescences of Liquidambar formosana Hance. LF is believed to unclog the meridians (Jingluo) in Traditional Chinese Medicine, and because it mainly affect the liver meridian which is considered closely related to mammary function, therefore LF has been used to treat some breast disease such as hypogalactia [1], mastitis [2], mammary duct ectasia [3], mammary gland hyperplasia [4], etc. Breast cancer is the severest breast disease threatened women's health as its high incidence rates and mortality rates [5]. Many natural products, including Chinese herbal medicines, have been used in breast cancer treatment, and pharmacological evidence has been accumulated for their application. In the previous research we found that betulonic acid, a triterpenoid come from LF, could inhibit human breast cancer MCF7 cells proliferation, and induce the cell cycle arrest and apoptosis [6]. Hence it is necessary to further investigate the chemical ingredients and the mechanism of antibreast cancer effect of LF.

Therefore, in the present study, 13 triterpenoids were identified and 6 of them were the first time isolated from LF. Considering that vast majority of the compounds reported in LF were triterpenoids [7-12], investigating macromolecular targets of LF triterpenoids could provide valuable information. Accordingly we adopted PharmMapper server as the computational tool which utilize a large-scale reverse pharmacophore mapping strategy [13]. On the other hand, we also collected the known and explored therapeutic protein targets of breast cancer. Because proteins do not function in isolation, and proteins which interact with the disease proteins may also play an important role in disease progression [14], thus we constructed protein-protein interaction (PPI) network to display associations between the predict targets of LF triterpenoids and the therapeutic targets of breast cancer. However, this guilt-by-association method generated a large PPI data set that needs further analysis to provide more effectively information [15]. Because cellular processes are mainly carried out by protein complexes [16], we identified the protein complexes from the PPI network using Molecular Complex Detection (MCODE) method, a graph theoretic clustering algorithm that detects densely connected regions that may represent molecular complexes [15, 17]. Molecular docking method could be used to analyses the conformations and orientations of the ligand binding to protein receptor, and predict molecular interactions and calculate binding energies [18], thus it was adopted to identify the targets that had high binding affinity to LF triterpenoids. Gene ontology (GO) enrichment analysis was finally conducted to reveal the biological process and signaling pathways that the identified targets were involved in. By means of the described methodology, this research could help us to acquire a better understanding about the anti-breast cancer potential and the traditional applications of LF.

\section{Methods \\ Chemical ingredients investigation}

Open column chromatography (CC) separation was carried out using silica gel (200-300 mesh) and Sephadex LH-20 as stationary phase. NMR spectra were run on a Bruker AVANCE II 600 spectrometer $(600 \mathrm{MHz}$ for $1 \mathrm{H}$ NMR and $150 \mathrm{MHz}$ for $13 \mathrm{C}$ NMR) with trimethylsilane as an internal standard. LF was collected in Jiangsu Province of China in February, 2014, and was identified by one of the authors, Prof. Dong-Fang Zhang. Voucher specimens have been deposited in the Department of pharmacognosy, School of Pharmacy, China Medical University (Liaoning, China).

LF (9 kg) was grinded and refluxed with $70 \%$ ethanol, and then concentrated under reduced pressure to afford a residue $430 \mathrm{~g}$. The residue was dispersed in water and successively extracted with cyclohexane and EtOAc, and 13 compounds were isolated from the EtOAc extraction (separation process was shown in Additional file 1). These compounds were determined using ${ }^{1} \mathrm{H}-\mathrm{NMR}$ and ${ }^{13} \mathrm{C}$ NMR spectrum analysis, and were identified by comparing the results with literature [7-12, 19-24, 75, 76].

\section{Targets exploration}

Absorption and metabolism properties of LF triterpenoids were predicted using admetSAR (http://lmmd. ecust.edu.cn/admetsar1) [23]. Potential targets of LF triterpenoids were predicted using PharmMapper server (http://www.lilab-ecust.cn/pharmmapper/) with the target set Human Protein Targets Only (v2010, 2241) [13]. The known and explored therapeutic targets of breast cancer (ICD10: C50) were collected from the Therapeutic Target Database (http://bidd.nus.edu.sg/group/ cjttd/) [24]. Target gene names were normalized using the Uniprot database (https://www.uniprot.org/) [25]. PPI network was constructed using the STRING database (version 10.5, https://string-db.org/) [26], and the network data was processed using Cytoscape software (version 3.6.1) [27] and the isolated nodes were removed. Three parameters, Degree, Closeness Centrality and Betweenness Centrality were used to assess the topological properties of the nodes in the PPI network, and higher values means more topological importance. The nodes whose values were less than the medians were defined as non-critical nodes and were removed from the PPI network. Then the network was analyzed using MCODE (version 1.5.1) [15], and the values of Degree cutoff, Node Score Cutoff, K-Core, Max Depth were 2, 0.2, 2, 100 , respectively. Four clusters were obtained and Cluster 4 was abandoned because it had only 3 nodes and 
contained no therapeutic targets. Cluster 3 was merged into cluster 2 . Then cluster 1 and 2 were used to create the compounds-predicted targets-therapeutic targets interaction networks, respectively.

\section{Molecular docking}

Crystal structures of protein targets were collected from the Protein Data Bank (PDB, http://www.rcsb.org/) [28] and inhibitors or agonists contained in the crystal structures were set as reference ligands. Besides, approved drugs or clinical trial drugs of the targets were collected from the Therapeutic Target Database and were also set as reference ligands (Additional file 2). Molecular docking experiments were performed at Molecular Operating Environment (MOE, 2018.01, Chemical Computing Group ULC). Pocket atoms were set as docking sites. A triangle matcher method was used as placement method. London dG scoring was used to select the top 30 poses (conformations and orientations of the ligand). Selected poses were refined in induced fit mode with the sidechains set as 'free to move' to achieve flexible receptor docking. GBVI/WSA dG scoring was finally used to select 5 poses with the lowest binding free energy, so a lower score means a more stable conformation.

\section{GO enrichment analysis}

GO enrichment analysis was performed using ClueGO (version 2.5.2) [29] and CluePedia (version 1.5.2) [30]. GO biological process and GO molecular function were employed as the annotation sources and result show only enriched terms with $p$ value $<0.01$. Network was created with kappa statistics and reflected the similarity of the terms' gene memberships. 0.4 kappa score was applied as threshold to create functional groups which were represented by their most significant term (leading term).

\section{Results}

Isolation and identification of LF triterpenoids

Thirteen triterpenoids were isolated from LF and were identified as betulonic acid (LF01), 28-nor- $\beta$-amyrenone (LF02), ambronal (LF03), betulin (LF04), oleanonic acid (LF05), ursonic acid (LF06), liquidambaric lactone (LF07), betulinic acid (LF08), epibetulinic acid (LF09),

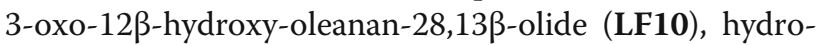
xyoleanonic lactone (LF11), $3 \alpha$-acetoxy-25-hydroxyolean-12-en-28-oic acid (LF12), Arjunolic acid (LF13), respectively. Six of them, LF03, LF04, LF05, LF08, LF09 and LF10 (NMR spectrums were shown in Additional file 3), were the first time isolated from LF. Other known triterpenoids contained in LF, including 6 $6 \beta-$ Hydroxy-3-oxo-lup-20(29)-en-28-oic acid (LFa), Oleanolic acid (LFb), Erythrodiol (LFc), 11 $\alpha$-Methoxy-28-nor$\beta$-amyrenone (LFd), $2 \alpha, 3 \beta$-dihydroxy-23-norolean-4(24), 12(13)-dien-28-oic acid (LFe), lantanolic acid (LFf) and ursolic acid (LFg), were collected from literature [7-12]. Among the 20 triterpenoids, LF01, LF04, LF08, LF09 and LFa belong to lupane-type triterpenoids, and LF06, LFg belong to ursane-type triterpenoids, and the others are oleanane-type triterpenoids (Fig. 1).

\section{Absorption and metabolism properties of LF triterpenoids Predicted ADME properties indicated that LF triterpenoids were appropriate for oral administration as they were classi- fied as HIA+ (human intestinal absorption was no less than $30 \%)$ and $\mathrm{Caco} 2+$ (Caco-2 permeability value (Papp) > $8 \times 10^{-6} \mathrm{~cm} / \mathrm{s}$ ) except LF12 and LF13 (HIA+, Caco2-). Al- though LF triterpenoids were labeled as P-glycoprotein sub- strates, LF02, LF03, LF04, LF07, LF10, LF11 and LFd were also potential P-glycoprotein inhibitors, which might facilitate the transport of other triterpenoids. With respect to the predicted metabolism properties, all the 20 triterpe- noids were the substrates of CYP450 3A4 and they did not inhibit the CYP450 metabolic activities.}

\section{Exploration of anti-breast cancer targets of LF triterpenoids}

Potential targets of LF triterpenoids were ranked according to the normalized fit score, and the top 100 targets were selected for each compound, then these targets were merged and 174 targets were finally obtained. On the other hand, 111 therapeutic targets (including 27 subtypes) of breast cancer were collected (Additional file 4). Based on these targets, 2 optimized compounds-predicted targets-therapeutic targets interaction networks were constructed (Fig. 2). The network contained 36 predicted targets and 35 therapeutic targets, which had 11 targets in common. The result indicated that the 36 predicted targets remained in the network were more closely related to breast cancer progression than the others.

\section{Molecular docking}

Molecular docking experiment was carried out on LF triterpenoids and the selected 36 targets except for calmodulin-1 (CALM1), eNOS (NOS3), serum albumin $(A L B), \mathrm{Mn}-\mathrm{SOD}$ (SOD2), BMP2 and placenta growth factor $(P G F)$ because no binding site for reference. Molecular docking results were summarized in Additional file 5 and Fig. 3. Eighteen of the 30 targets, including ErbB4 (ERBB4), EGFR, CDK2, CDK6, p38 MAPK (MAPK14), ERK2 (MAPK1), Lck (LCK), Src (SRC), IGF1R, PI3KY (PIK3CG), VEGFR2 (KDR), aromatase (CYP19A1), PTP1B (PTPN1), SHP2 (PTPN11), caspase-3 (CASP3), PARP-1, HSP90 $\alpha$ (HSP90AA1) and HSC70 (HSPA8), were identified as the anti-breast cancer targets of LF triterpenoids. To acquire a better understanding about the results, 


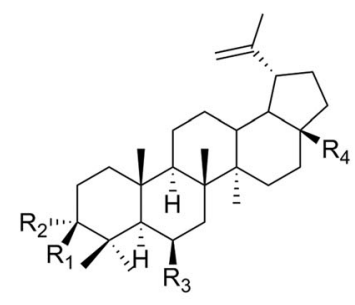

LF01. R1+R2=O, R3=H, R4 $=\mathrm{COOH}$ LF04. R1 $=\mathrm{OH}, \mathrm{R} 2=\mathrm{R} 3=\mathrm{H}, \mathrm{R} 4=\mathrm{CH}_{2} \mathrm{OH}$ LF08. R1 $=\mathrm{OH}, \mathrm{R} 2=\mathrm{R} 3=\mathrm{H}, \mathrm{R} 4=\mathrm{COOH}$ LF09. R1 $=\mathrm{R} 3=\mathrm{H}, \mathrm{R} 2=\mathrm{OH}, \mathrm{R} 4=\mathrm{COOH}$ LFa. R1+R2=O, R3=OH, R4 $=\mathrm{COOH}$

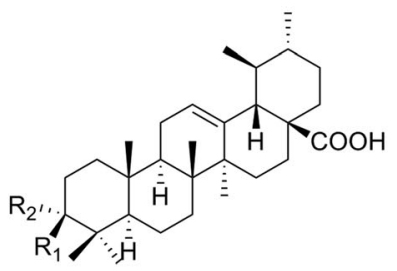

LF06. $\mathrm{R} 1+\mathrm{R} 2=\mathrm{O}$ LFg. $\mathrm{R} 1=\mathrm{OH}, \mathrm{R} 2=\mathrm{H}$

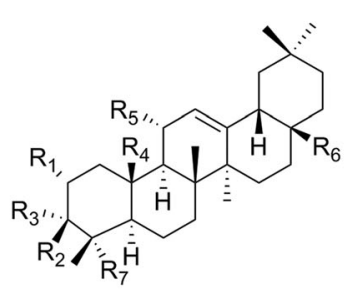

LF02. R1=R5=R6=H, R2+R3=O, R4=R7= $\mathrm{CH}_{3}$ LF03. R1=R5=H, R2+R3=O, R4=R7= $\mathrm{CH}_{3}, \mathrm{R} 6=\mathrm{CHO}$ LF05. R1=R5=H, R2+R3=O, R4=R7= $\mathrm{CH}_{3}, \mathrm{R} 6=\mathrm{COOH}$ LF12. $\mathrm{R} 1=\mathrm{R} 2=\mathrm{R} 5=\mathrm{H}, \mathrm{R} 3=\mathrm{OCOCH}_{3}, \mathrm{R} 4=\mathrm{CH}_{2} \mathrm{OH}$, $\mathrm{R} 6=\mathrm{COOH}, \mathrm{R} 7=\mathrm{CH}_{3}$

LF13. R1=R2=OH, R3=R5=H, R4= $\mathrm{CH}_{3}, \mathrm{R} 6=\mathrm{COOH}$, $\mathrm{R} 7=\mathrm{CH}_{2} \mathrm{OH}$

LFb. R1=R3=R5=H, R2=OH, R4=R7= $\mathrm{CH}_{3}, \mathrm{R} 6=\mathrm{COOH}$

LFc. R1=R3=R5=H, R2=OH, R4=R7= $\mathrm{CH}_{3}, \mathrm{R} 6=\mathrm{CH}_{2} \mathrm{OH}$

LFd. $\mathrm{R} 1=\mathrm{R} 6=\mathrm{H}, \mathrm{R} 2+\mathrm{R} 3=\mathrm{O}, \mathrm{R} 4=\mathrm{R} 7=\mathrm{CH}_{3}, \mathrm{R} 5=\mathrm{OCH}_{3}$

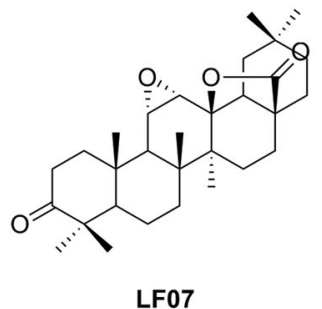

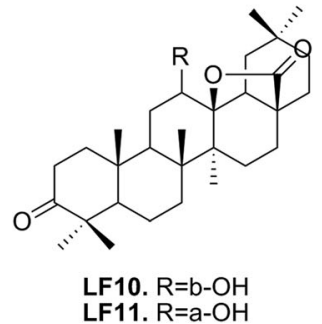

LF11. $\mathrm{R}=\mathrm{a}-\mathrm{OH}$

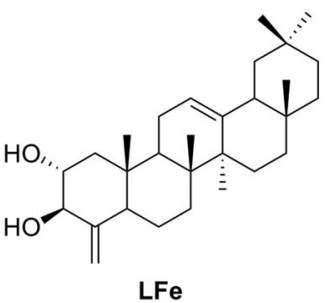

$\mathrm{LFe}$

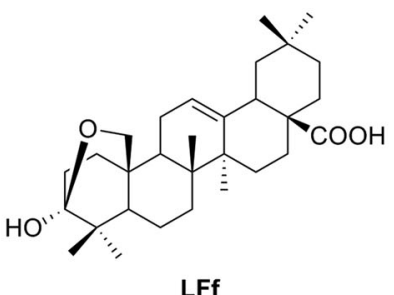

LFf

Fig. 1 Chemical structures of the 20 triterpenoids contained in LF. LF1 13 were isolated from LF and LF03, LF04, LF05, LF08, LF09 and LF10 were the first time isolated from LF. LFa $\sim \mathbf{g}$ were collected from literature

binding characteristics and functions of these targets were analyzed as follows.

\section{Targets that belong to protein kinases family}

Half of the 30 targets belong to protein kinase superfamily, among which 14 targets were protein tyrosine kinases or CMGC serine/threonine protein kinases (Additional file 6). These two types of protein kinases play important roles in cancer progression and they are promising targets in breast cancer therapy [31, 32]. The catalytic domain of protein tyrosine kinases have high homology with that of serine/threonine protein kinase [33], which may explain why LF triterpenoids showed the features of ATP-competitive inhibitors targeting both the two types of protein kinases.

EGFR subfamily members (belonging to receptor tyrosine kinases) play critical role in the pathogenesis of breast cancer. Besides the well-known EGFR (ErbB1/
HER1) and ErbB2 (HER2, ERBB2), there is growing concern about another family member ErbB4 (HER4, $E R B B 4)$. Clinical studies suggested that to the patients with advanced stage or triple-negative breast cancer, increased expression of ErBb4 is associated with poor prognosis [34, 35]. Molecular docking result showed that hydrophobic skeleton is a favorable factor for LF triterpenoids to stabilize at the ATP binding site of ErbB4 (Fig. 4a). For active protein kinases, K/E/D/D signature motif plays important structural and catalytic roles [36]. It can be observed that Lys751 (the $\mathrm{K}$ of $\mathrm{K} / \mathrm{E} / \mathrm{D} / \mathrm{D}$ in ErbB4) [37] formed a salt bridge with Asp861, therefore the $-\mathrm{NH}^{+}$group of Lys751 could be a stable hydrogen bond donor to LF triterpenoids (Fig. 4b). For most of the LF triterpenoids, hydrogen bond donor electrostatically preferred locations were at the opposite ends of skeleton: substituent located at C-17 and C-3 (Fig. 4c, Table 1). In the LF01-ErbB4 complex, it was the 17- 


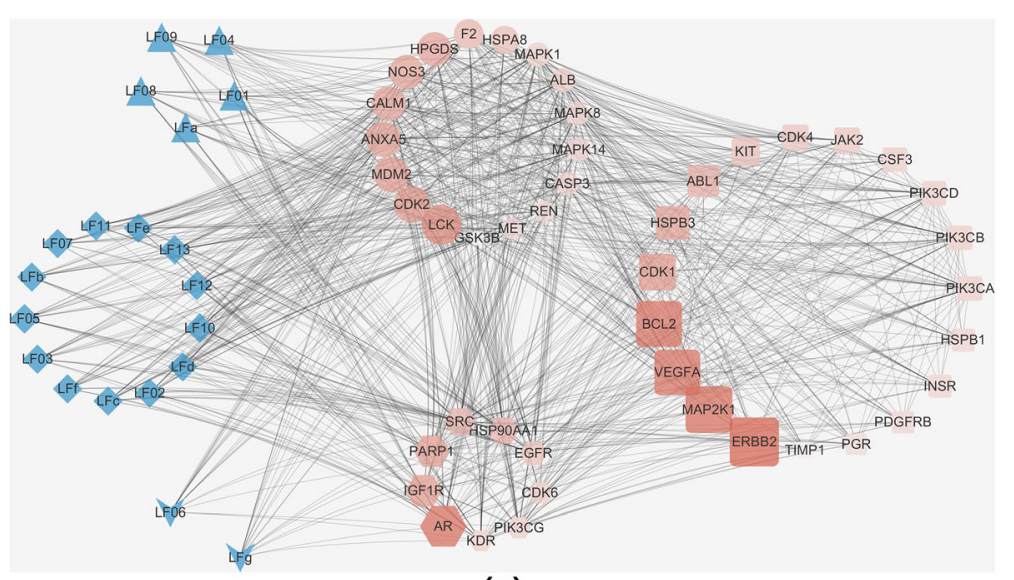

(a)

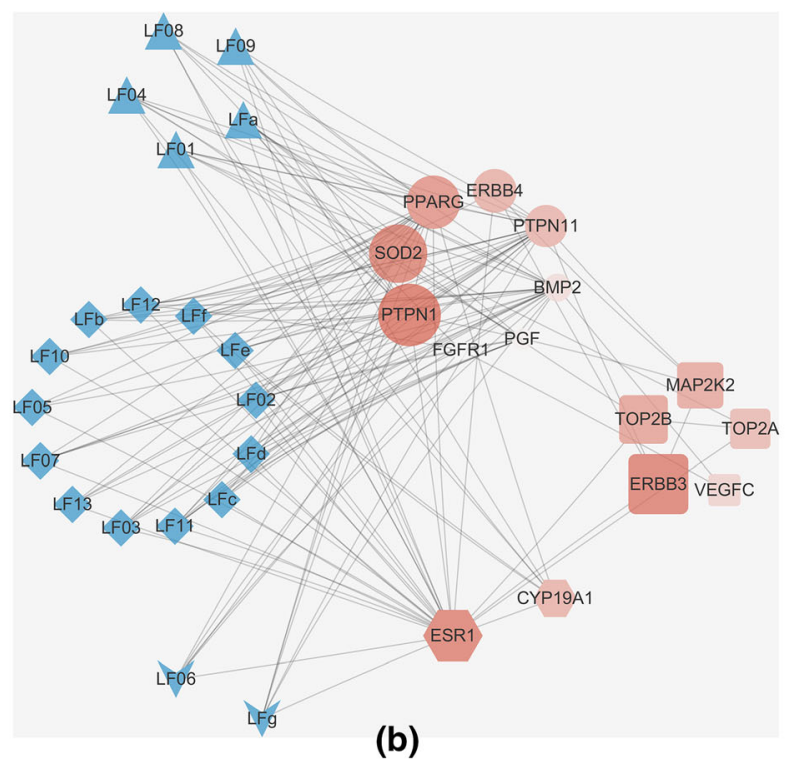

Fig. 2 Compounds-predicted targets-therapeutic targets interaction networks 1 (a) and 2 (b). Protein targets are represented by their gene names; $\boldsymbol{\Lambda}$ represents lupane-type triterpenoids; represents oleanane-type triterpenoids; $\boldsymbol{\nabla}$ represents ursane-type triterpenoids; $\bullet$ represents the predicted targets of LF triterpenoids; represents the therapeutic targets of breast cancer; represents the targets share by predicted targets and therapeutic targets. The layouts of each type of target nodes are determined by their MCODE score, and the setting is high values to big sizes and dark colors, indicating a more important role in the network

carboxyl group bound to Lys751 (Fig. 4d); in the other LF triterpenoids-ErbB4 complexes, however, it was the C-3 substituent (Table 1). Among the three types of LF triterpenoids, lupane-type triterpenoids could form more stable hydrogen bonds with Lys751 because of the low binding energies, and the most stable hydrogen bond came from LF01. However, LF04 could not form strong interaction with Lys751 might because the 17-carboxyl group was displaced by hydroxymethyl group. LF triterpenoids bound to EGFR in a similar fashion, but Lys745 (the $\mathrm{K}$ of $\mathrm{K} / \mathrm{E} / \mathrm{D} / \mathrm{D}$ in EGFR) [37] bound to the 17-carboxyl group more often than the C-3 substituent, and the most stable hydrogen bonds came from LF05 and LFg (Table 1). However, lupane-type triterpenoids did not show strong interactions with EGFR, which meant that lupane-type triterpenoids from LF might have higher affinity and inhibition to ErbB4 than EGFR.

CDKs (belonging to CMGC serine/threonine protein kinase family) are also important anti-breast cancer targets. Although selective CDK4/6 inhibition results in less toxicity, a huge challenge is that breast cancer (including basal-like breast cancer) adapt quickly to CDK4/6 inhibition, while inhibiting CDK2 simultaneously is an effective solution [38, 39]. Molecular docking result showed that most LF triterpenoids could bind with both CDK6 and CDK2. In LF triterpenoids-CDK6 complexes, binding sites were catalytic loop (especially was Lys147) and 


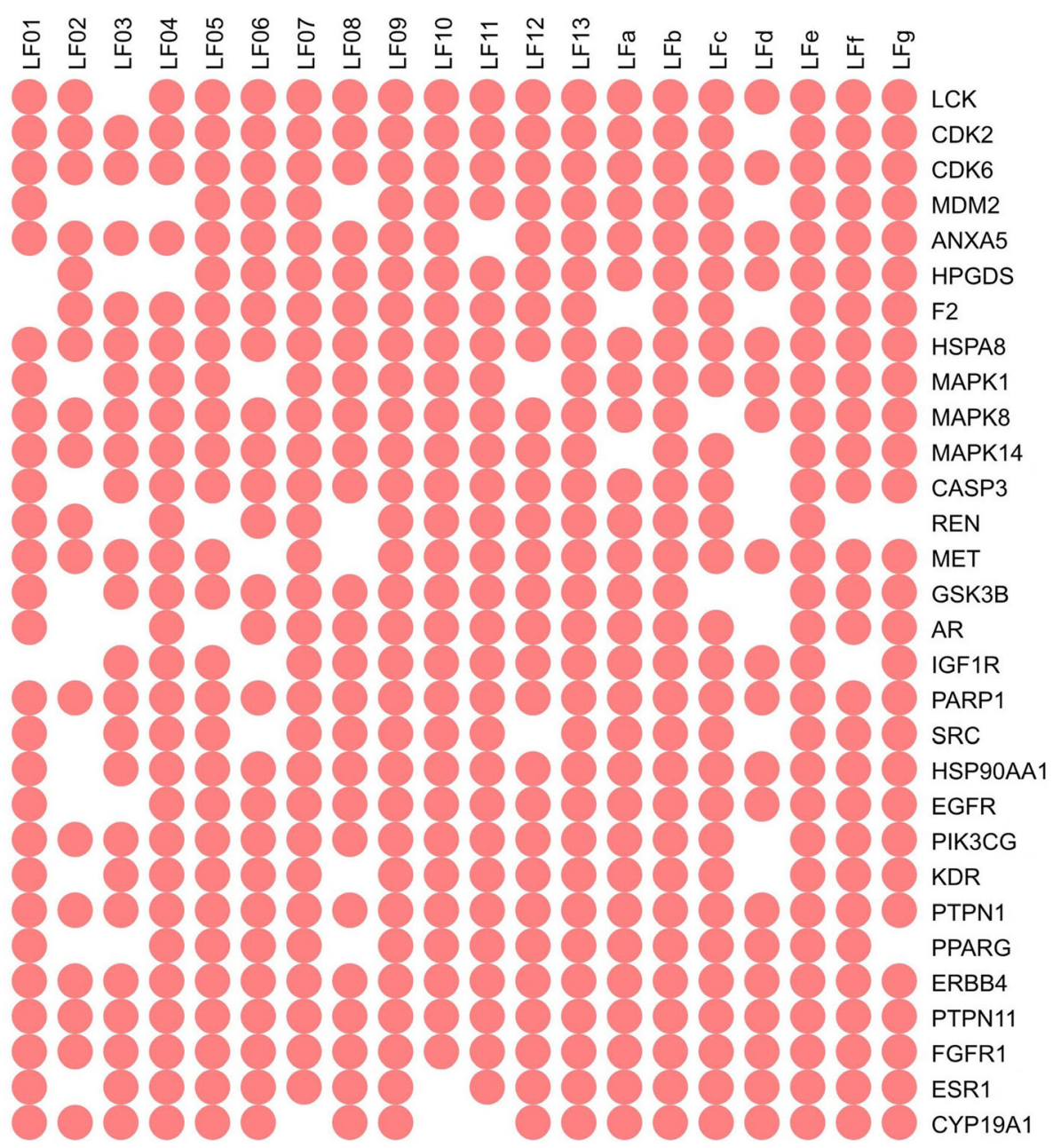

Fig. 3 A brief summary of molecular docking result. Protein targets are represented by their gene names. Red spots means binding interactions exist between $L F$ triterpenoids and targets

activation segment (especially was Asp163, the D of DFG and the second $\mathrm{D}$ of $\mathrm{K} / \mathrm{E} / \mathrm{D} / \underline{\mathrm{D}})$. In LF triterpenoids-CDK2 complexes, however, binding sites mainly were hinge residues (Asp86, Gln85, His84 and Leu83) and the K of K/E/ $\mathrm{D} / \mathrm{D}$ (Lys33) (Table 2). Because hinge region played an important role in inhibitor binding [40], the result indicated that LF triterpenoids probably had a higher inhibitory activity to CKD2 than CDK6.

It was reported that phosphorylated MAPKs including ERK2 (MAPK1), JNK1 (MAPK8) and p38 MAPK (MAPK14) over-expressed in breast cancer patients and is associated with poor prognosis [41-43]. Molecular docking result showed that LF triterpenoids could bind to the hinge region (Thr106, His107, Met109 and Gly110) and the DFG motif (Asp168 and Phe169) of p38 MAPK, but in LF triterpenoids-ERK2 complexes the interactions were weaker, and LF triterpenoids could not form hydrogen bonds with the hinge region of JNK1
(Table 3), indicating LF triterpenoids had higher inhibitions to p38 MAPK than ERK2 and JNK1. Lck (LCK) plays a pathological role in breast cancer progression probably by activating MAPK signaling pathway [4446]. Molecular docking result showed that LF triterpenoids could bind with key residues of Lck including the conserved ATP binding lysine (Lys273), the linker sequence between the SH2 domain and the catalytic domain (Ser323), the catalytic domain (Ala368 and Asn369) and the activation loop (Asp382, Glu390, Tyr394, Thr395, and Arg397), which meant that LF triterpenoids could compete with ATP for binding Lck and inhibit its activity.

In addition, Src $(S R C)$, VEGFR2 (KDR), IGF1R and PI3K $\gamma$ (PIK3CG) have already been successful targets in breast cancer therapy. Molecular docking result showed that LF triterpenoids could bind with these protein kinases and act as ATP competitive inhibitors. 


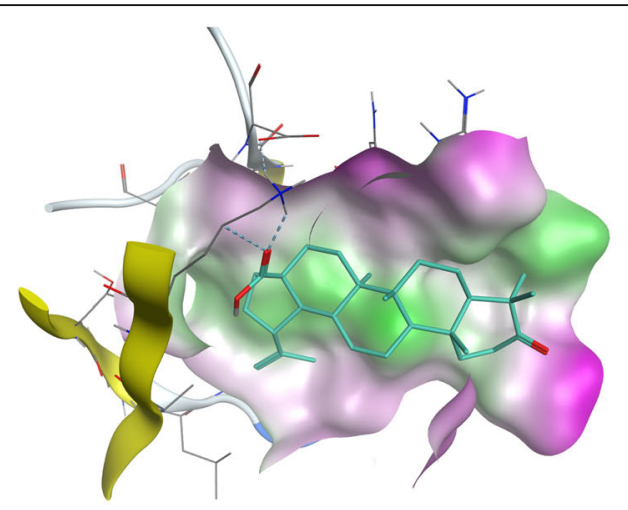

(a)

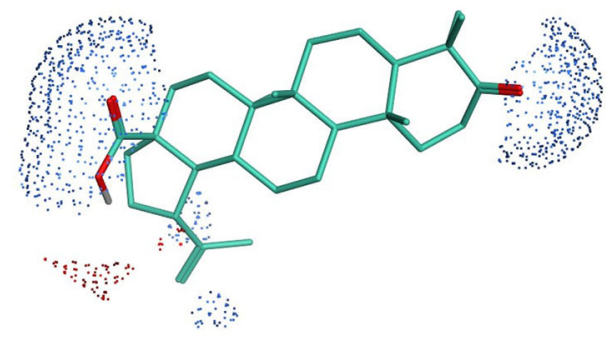

(c)

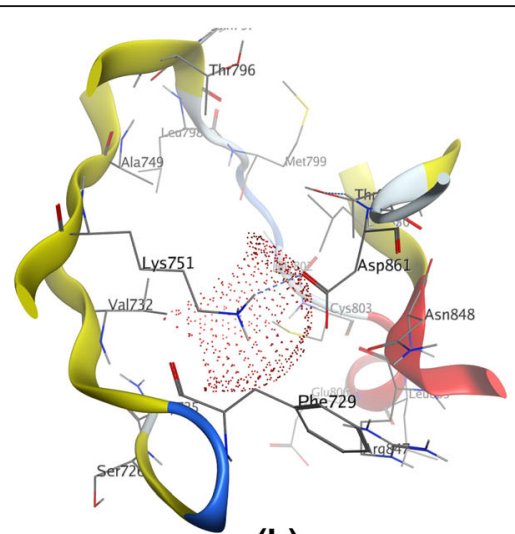

(b)

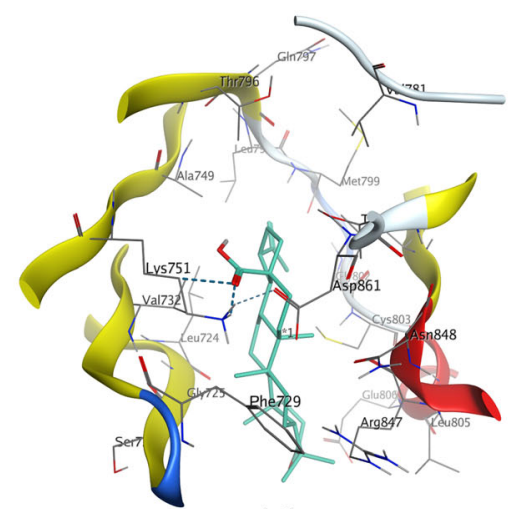

(d)

Fig. 4 Binding interaction between LF01 and ErbB4. a Molecular surface of the ATP binding pocket of ErBb4, colored by lipophilicity: green for hydrophobic, white for neutral and purple for hydrophilic regions. b Electrostatic map of Lys751 in the catalytic domain of ErbB4. Electrostatically preferred locations of hydrogen bond acceptor are colored red. c Electrostatic map of LF01. Electrostatically preferred locations of hydrogen bond donor are colored blue. $\mathbf{d}$ The 17-carboxyl group of LF01 could form hydrogen bond with Lys751 in the binding site of ErbB4

\section{Targets that belong to nuclear hormone receptor family and cytochrome P450 family}

For nuclear hormone receptors ER $\alpha$ (ESR1), AR and PPARY (PPARG), both agonist and antagonist bind at the same site of LBD, therefore it's hard to figure out whether the ligand were agonist or antagonist through molecular docking result. Besides, AR and PPAR $\gamma$ are still complicated targets for breast cancer treatment because studies gave contradictory conclusions [47, 48]. Hence effects of LF triterpenoids caused by binding with these 3 targets need further studies. Human cytochrome P450 aromatase (AROM, CYP19A1) use androgens as substrates with high specificity and catalyze them to estrogens [49], and its inhibitors, such as exemestane, were used to treat breast cancer for many years. Molecular docking result showed that LF triterpenoids could compete with testosterone for binding aromatase, forming hydrogen bonds with Met374 and Arg115 in the catalytic cleft, and it is remarkable that LF triterpenoids had more stable conformations (with scores from -8.1861 to
- 9.3923) than testosterone (with scores from -6.5824 to -7.8243 ) and exemestane (scores - 7.7675) in the binding pocket, indicating that LF triterpenoids might be promising inhibitors of aromatase.

\section{PTPs}

Although PTP1B (PTPN1) was previously known could dephosphorylate some receptor protein tyrosine kinases, studies showed that inhibition of PTP1B could be a new therapeutic strategy for breast cancer, including triple-negative breast cancer [50, 51]. The catalytic domain of PTP1B can be divided into four sites and A site is catalytic pocket. However because of the high homology of the catalytic domain between PTP1B and TCPTP (a phosphatase related to regulating T-cell activation), inhibitors only binding to A site have low selectivity $[52,53]$. Molecular docking result showed that LF triterpenoids could bind on A site (Ala217, Gly220, Arg221, Gln266), C site (Tyr46, Arg47 and Asp48) and D site (Glu115, Lys116, 
Table 1 Binding interactions between LF triterpenoids and Lys751 of ErbB4/Lys 745 of EGFR

\begin{tabular}{|c|c|c|c|c|c|c|c|}
\hline \multirow[t]{2}{*}{ Skeleton } & \multirow[t]{2}{*}{ Compounds } & \multicolumn{3}{|c|}{ Binding with Lys751 of ErbB4 } & \multicolumn{3}{|c|}{ Binding with Lys745 of EGFR } \\
\hline & & Substituent & $\mathrm{E}^{\mathrm{a}}(\mathrm{kcal} / \mathrm{mol})$ & Scores $^{\mathbf{b}}$ & Substituent & $\mathrm{E}^{\mathrm{a}}(\mathrm{kcal} / \mathrm{mol})$ & Scores $^{\mathbf{b}}$ \\
\hline \multirow[t]{5}{*}{ Lupane-type } & LF01 & $17-\mathrm{COOH}$ & -9.8 & -5.9640 & $17-\mathrm{COOH}$ & -2.1 & -7.0066 \\
\hline & LF04 & $3 \beta-\mathrm{OH}$ & -0.8 & -5.6831 & $3 \beta-\mathrm{OH}$ & -0.6 & -6.2663 \\
\hline & LF08 & $3 \beta-\mathrm{OH}$ & -8.3 & -6.1819 & & & \\
\hline & LF09 & $3 a-O H$ & -5.4 & -6.3759 & & & \\
\hline & $\mathrm{LFa}$ & $3=0$ & -6.3 & -5.4535 & & & \\
\hline \multirow[t]{11}{*}{ Oleanane-type } & LF03 & $3=0$ & -2.4 & -5.8667 & & & \\
\hline & LF05 & $3=0$ & -4.3 & -5.8143 & $17-\mathrm{COOH}$ & -11.2 & -6.6884 \\
\hline & LF07 & $3=0$ & -2.3 & -5.9734 & & & \\
\hline & LF11 & & & & $12 \mathrm{a}-\mathrm{OH}$ & -1.4 & -6.3773 \\
\hline & LF12 & $3 \mathrm{a}-\mathrm{OCOCH}_{3}$ & -6.1 & 5.9681 & $17-\mathrm{COOH}$ & -2.1 & -6.9071 \\
\hline & LF13 & $3 \beta-\mathrm{OH}$ & -5.3 & -6.2568 & $17-\mathrm{COOH}$ & -0.8 & -6.7261 \\
\hline & $\mathrm{LFb}$ & & & & $17-\mathrm{COOH}$ & -1.1 & -6.8580 \\
\hline & LFC & $3 \beta-\mathrm{OH}$ & -8.0 & -5.9229 & & & \\
\hline & LFd & $11-\mathrm{OCH}_{3}$ & -4.9 & -6.1058 & & & \\
\hline & LFe & $3 \beta-\mathrm{OH}$ & -0.6 & -5.5257 & & & \\
\hline & LFf & $3 a-O H$ & -1.4 & -5.7394 & $3 a-O H$ & -4.5 & -5.9924 \\
\hline Ursane-type & $\mathrm{LFg}$ & & & & $17-\mathrm{COOH}$ & -9.0 & -6.9074 \\
\hline
\end{tabular}

${ }^{a}$ The lowest binding energy; ${ }^{b}$ Scores of the conformations with the lowest binding energy

Table 2 Binding site of LF triterpenoids in CDK2 and CDK6

\begin{tabular}{|c|c|c|c|}
\hline Skeleton & Compounds & Binding site in CDK2 & Binding site in CDK6 \\
\hline \multirow[t]{5}{*}{ Lupane-type } & LF01 & hinge residues, catalytic loop & catalytic loop \\
\hline & LF04 & hinge residues & catalytic loop, activation segment \\
\hline & LF08 & & catalytic loop, activation segment \\
\hline & LF09 & $\mathrm{K}$ of $\mathrm{K} / \mathrm{E} / \mathrm{D} / \mathrm{D}$ & catalytic loop \\
\hline & LFa & hinge residues, $\mathrm{K}$ of K/E/D/D & catalytic loop \\
\hline \multirow[t]{13}{*}{ Oleanane-type } & LF02 & $\mathrm{K}$ of $\mathrm{K} / \mathrm{E} / \mathrm{D} / \mathrm{D}$ & catalytic loop \\
\hline & LF03 & hinge residues, $\mathrm{K}$ of K/E/D/D & catalytic loop \\
\hline & LF05 & hinge residues, catalytic loop, activation segment & catalytic loop \\
\hline & LF07 & hinge residues & catalytic loop \\
\hline & LF10 & hinge residues & catalytic loop, activation segment \\
\hline & LF11 & hinge residues & catalytic loop, activation segment \\
\hline & LF12 & hinge residues, $\mathrm{K}$ of K/E/D/D & catalytic loop \\
\hline & LF13 & hinge residues, $\mathrm{K}$ of $\mathrm{K} / \mathrm{E} / \mathrm{D} / \mathrm{D}$ & catalytic loop \\
\hline & $\mathrm{LFb}$ & hinge residues, $\mathrm{K}$ of $\mathrm{K} / \mathrm{E} / \mathrm{D} / \mathrm{D}$, catalytic loop & catalytic loop \\
\hline & LFC & hinge residues, $\mathrm{K}$ of $\mathrm{K} / \mathrm{E} / \mathrm{D} / \mathrm{D}$, catalytic loop & \\
\hline & LFd & & catalytic loop \\
\hline & LFe & catalytic loop, activation segment & activation segment \\
\hline & LFf & K of K/E/D/D, catalytic loop & activation segment \\
\hline \multirow[t]{2}{*}{ Ursane-type } & LF06 & & activation segment \\
\hline & $\mathrm{LFg}$ & hinge residues, $\mathrm{K}$ of $\mathrm{K} / \mathrm{E} / \mathrm{D} / \mathrm{D}$ & catalytic loop \\
\hline
\end{tabular}


Table 3 Binding interactions between LF triterpenoids and the hinge region of p38 MAPK/ERK2

\begin{tabular}{|c|c|c|c|c|c|}
\hline \multirow[t]{2}{*}{ Skeleton } & \multirow[t]{2}{*}{ Compounds } & \multicolumn{2}{|c|}{ Binding with p38 MAPK } & \multicolumn{2}{|c|}{ Binding with ERK2 } \\
\hline & & $\mathrm{E}^{\mathrm{a}}(\mathrm{kcal} / \mathrm{mol})$ & Scores $^{b}$ & $\mathrm{E}^{\mathrm{a}}(\mathrm{kcal} / \mathrm{mol})$ & Scores $^{b}$ \\
\hline \multirow[t]{4}{*}{ Lupane-type } & LF01 & $-2.9 \sim-3.2$ & $-7.6148 \sim-7.6724$ & $-0.7 \sim-1.5$ & $-6.7461 \sim-6.9596$ \\
\hline & LF04 & $-1.1 \sim-1.7$ & $-7.3417 \sim-7.9353$ & $-1.0 \sim-1.3$ & $-7.0514 \sim-7.0586$ \\
\hline & LF08 & $-0.7 \sim-1.6$ & $-7.7455 \sim-8.1666$ & -1.0 & -7.0391 \\
\hline & LF09 & -1.5 & -8.3157 & $-1.1 \sim-2.8$ & $-6.7530 \sim-6.8403$ \\
\hline \multirow[t]{9}{*}{ Oleanane-type } & LF05 & $-1.8 \sim-2.9$ & $-7.7640 \sim-8.0353$ & & \\
\hline & LF07 & & & -0.9 & -6.5656 \\
\hline & LF10 & & & $-1.2 \sim-1.7$ & $-6.9311 \sim-7.5512$ \\
\hline & LF11 & -1.0 & -7.1710 & & \\
\hline & LF12 & -0.7 & -8.3375 & & \\
\hline & LF13 & $-1.4 \sim-2.5$ & $-8.2020 \sim-8.2068$ & & \\
\hline & LFb & $-1.3 \sim-2.6$ & $-7.3082 \sim-7.7737$ & & \\
\hline & LFe & -0.7 & -7.8543 & $-1.0 \sim-1.9$ & $-6.4379 \sim-6.9347$ \\
\hline & LFf & $-1.3 \sim-4.3$ & $-7.9048 \sim-8.1671$ & & \\
\hline \multirow[t]{2}{*}{ Ursane-type } & LF06 & -2.3 & -7.9031 & & \\
\hline & LFg & -1.4 & -8.0787 & & \\
\hline
\end{tabular}

${ }^{\mathrm{a}}$ binding energy; ${ }^{\mathrm{b}}$ Scores of the conformations that binding with the hinge region of p38 MAPK or ERK2

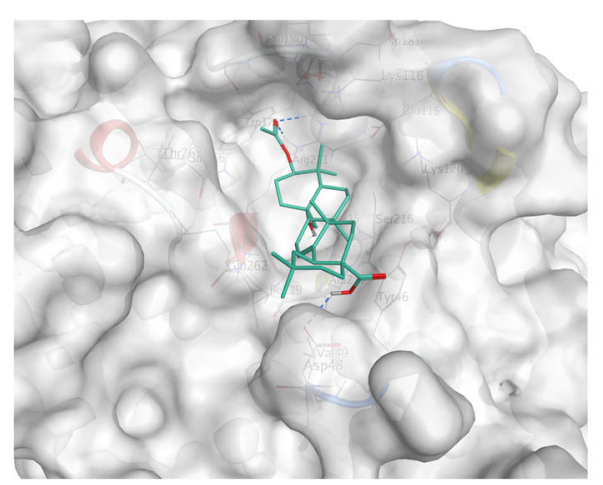

(a)

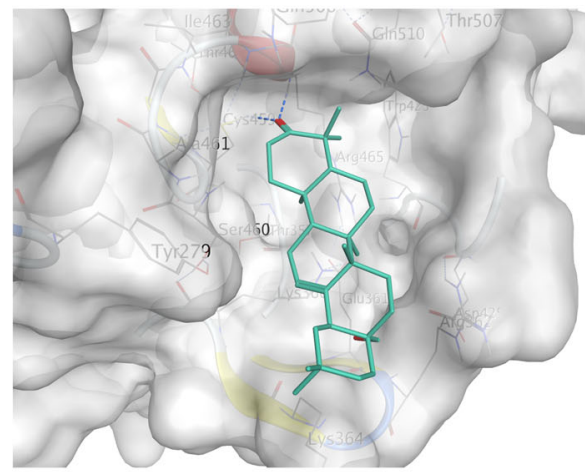

(c)

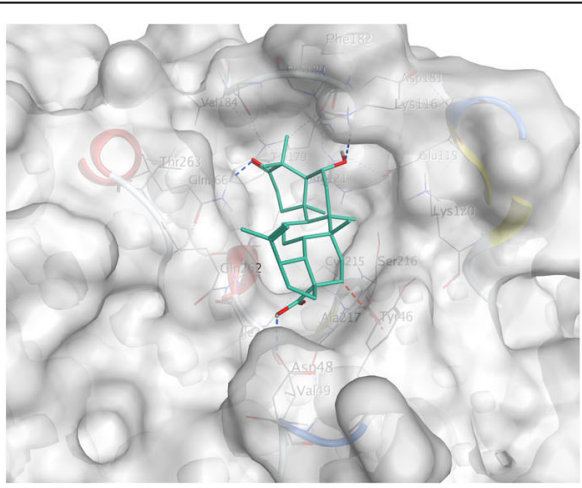

(b)

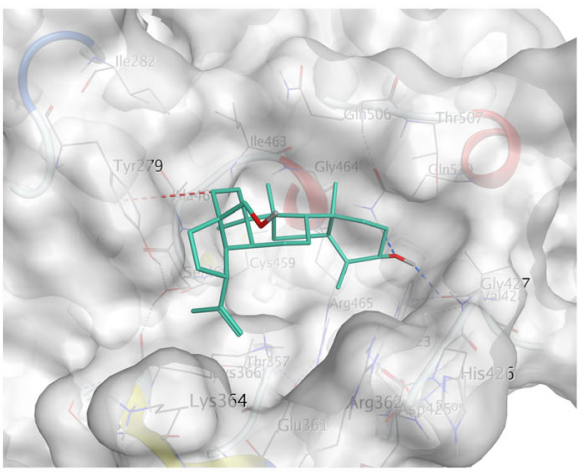

(d)

Fig. 5 Binding sites of LF triterpenoids on PTP1B and SHP2. a LF12 could bind with PTP1B at Arg221 on A site, and Asp48 on C site; $\mathbf{b}$ LFa could bind with PTP1B at Gln266 on A site, Tyr46 and Asp48 on C site, and Lys116 on D site; c LF03 could bind with SHP2 at Cys459 and Arg465 in Ploop; d LF04 could bind with SHP2 at Gly427 in WPD loop, and Tyr279 in pTyr recognition loop 
Asp181). Lys116 on D site was a preferred residue to half of LF triterpenoids, such as LF05, LF06 and LF12 (the lowest binding energy was-9.1, -8.3 and -9.0 $\mathrm{kcal} / \mathrm{mol}$, respectively), but could not form bond with LF triterpenoids without 17-carboxyl group. Nearly half of LF triterpenoids could bind with more than one site, such as LF12 (occupied AC sites) and LFa (occupied ACD sites) (Fig. 5a, b). These characters of LF triterpenoids probably could increase their selectivity and inhibitory activity to PTP1B.

SHP2 (PTPN11) is required for the full activation of MAPK signaling pathway and could promotes breast cancer (including triple-negative breast cancer) progression $[54,55]$. Important binding sites for SHP2 inhibitors include P-loop (the PTP signature motif for recognition of phosphoryl moiety in substrate), WPD loop (lid of the active site pocket) and $p$ Tyr recognition loop [56]. Molecular docking result of SHP2 showed that LF triterpenoids could bind with Cys459 and Arg465 in P-loop (such as LF03), and Gly427 in the flexible WPD loop, and form $\mathrm{C}-\mathrm{H} \cdot \cdots \pi$ interaction with Tyr279 in $p$ Tyr recognition loop (such as LF04) (Fig. 5c, d). Besides, about half of LF triterpenoids could form hydrogen bond with the side chain of Lys366, such as LF05, LF12 and LFg (the lowest binding energy was $-8.5,-8.2$ and $-9.9 \mathrm{kcal} / \mathrm{mol}$, respectively).

\section{Targets related to apoptosis}

Although the proteolytic enzyme caspase-3 (CASP3) could initiates apoptosis by cleaving and inactivating PARP1, it also could stimulate survived breast cancer cell growth by promoting PGE2 release [57]. Molecular docking result showed that LF triterpenoids could bind with caspase-3 like its inhibitors. However, LF triterpenoids could promote apoptosis by directly inhibiting PARP1. PARP1 is a base excision repair protein that could promote cancer cell survival, and is an effective target in triple-negative breast cancer [58, 59]. Molecular docking result showed that C-17 substituent of LF triterpenoids could form hydrogen bound with the backbone of Arg878 (or the sidechain of Asp770) on adenine ribose binding site (AD site) of PARP1, such as LF08 (Fig. 6a). And binding the AD site is considered to gain selectivity for the inhibitors [60]. Besides, some LF triterpenoids could form $\mathrm{C}-\mathrm{H} \cdots \pi$ interaction with Tyr896 in nicotinamide binding pocket (NI site), or form hydrogen bound with Asp766 and Glu763 on phosphate binding site (PH site), such as LFc (Fig. 6b). The result indicated that LF triterpenoids could compete with $\mathrm{NAD}^{+}$for binding PARP1 then inhibit its activity.

Molecular chaperones HSP90 $\alpha$ (HSP90AA1) and HSC70 (HSPA8) could assist the stability and function of many oncogenic proteins then keep cancer cells

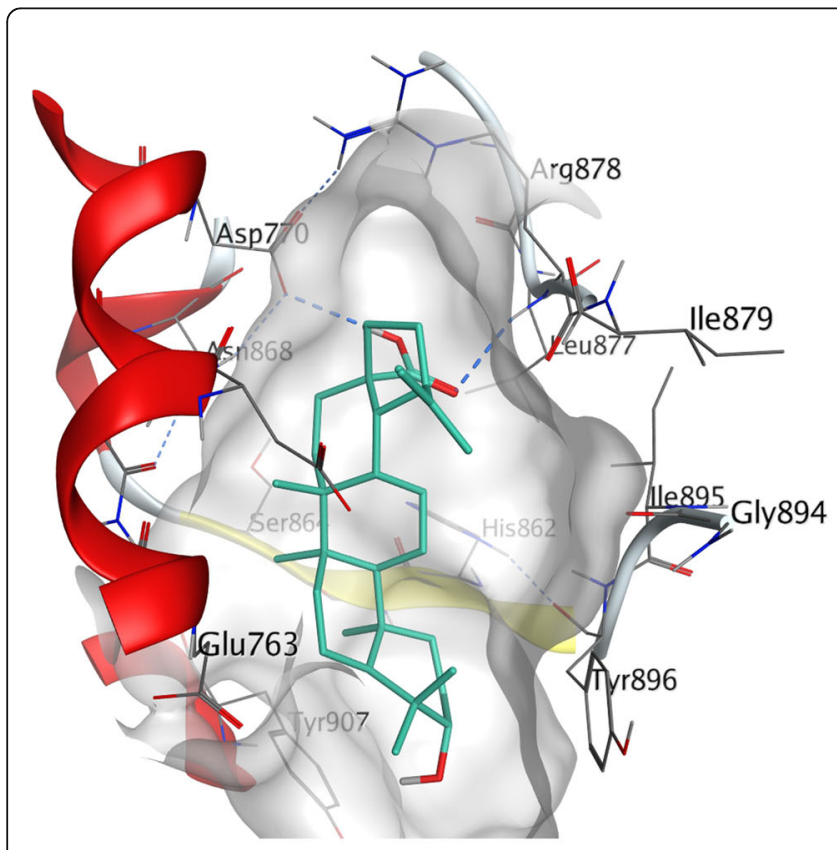

(a)

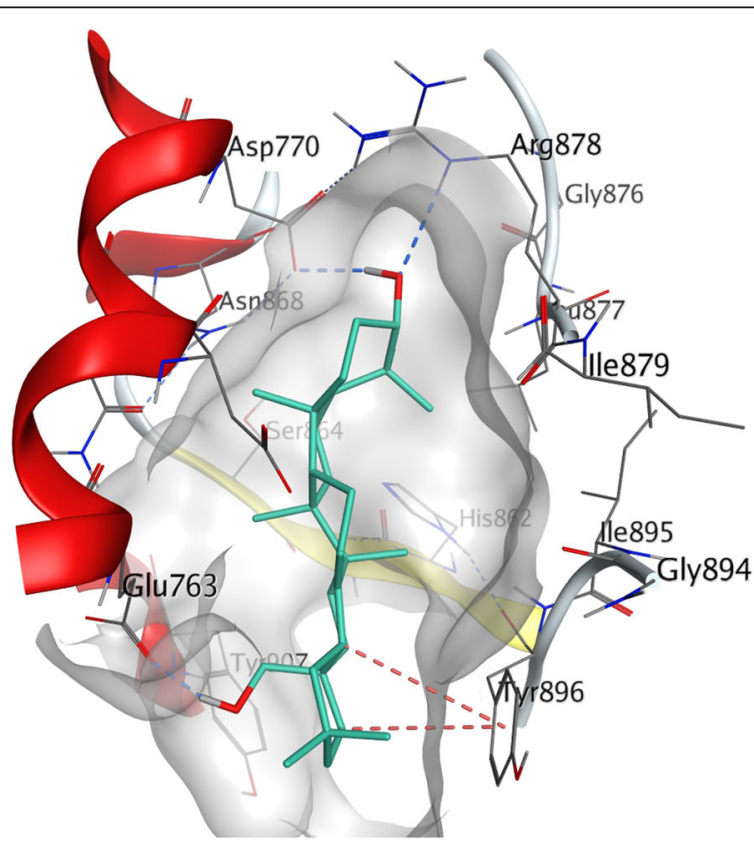

(b)

Fig. 6 Binding sites of LF triterpenoids on PARP1. a LF08 could form hydrogen bound with the backbone of Arg878 and the sidechain of Asp770 on AD site; $\mathbf{b}$ Besides binding on AD site, LFc could form C-H...T interaction with Tyr896 on NI site, and form hydrogen bound with Glu763 on PH site 
surviving [61]. Molecular docking result showed that LF triterpenoids could bind with HSP90 $\alpha$ and HSC70 at ATP binding site, indicating they may act as HSPs' inhibitors then promote cell death.

The p53 protein can initiate apoptosis while its negative regulator MDM2 could bind and inactive p53 thus acts as a tumor promoter [62]. Molecular docking result showed that LF triterpenoids could occupy the hydrophobic pockets of MDM2 that bind with p53, and formed hydrogen bonds with residues Met62, Tyr67, Tyr100, or formed C-H... $/ \mathrm{O}-\mathrm{H} \cdot \cdots \pi$ interactions with His96, but these interactions were not strong enough (binding energy $-0.6 \sim-2.9 \mathrm{kcal} / \mathrm{mol}$ ) to compete with the macromolecule $\mathrm{p} 53$, indicating LF triterpenoids might be not high affinity MDM2 antagonists.

\section{Other targets}

HPGDS catalyzes the conversion of $\mathrm{PGH}_{2}$ to $\mathrm{PGD}_{2}$, and closely related to the progression of inflammation. Although its role in breast cancer is not entirely clear, it is reported that HPGDS suppress gastrointestinal cancer progression [63, 64]. However, molecular docking result showed that LF triterpenoids (except for LF01 and LF04) could form hydrogen bonds and $\mathrm{C}-\mathrm{H} \cdots \pi / \mathrm{O}-\mathrm{H} \cdots \pi \mathrm{\pi}$ interactions with Arg14 and Trp104 of HPGDS, which are important residues for binding affinity and binding pocket stability, indicating LF triterpenoids could compete with $\mathrm{PGH}_{2}$ for binding HPGDS and acting as an inhibitor.

For other targets including annexin A5 (ANXA5), prothrombin ( $F 2)$ and renin $(R E N)$, there was no firm evidence to link their functions directly to breast cancer progression, and they were less significant in the PPI network, which meant that they might be not important targets for LF triterpenoids.

\section{GO enrichment analysis}

GO enrichment analysis was conducted on the 18 identified targets according to the molecular docking result. As a result, totaling 29 terms were acquired, and they could be clustered into 7 functional groups (Additional file 7). The biggest group that covered $44.19 \%$ of enriched terms was peptidyl-tyrosine autophosphorylation group, indicating that inhibition of protein tyrosine kinases autophosphorylation might be the primary mechanism for the anti-breast cancer effect of LF triterpenoids. Figure 7 revealed that the most relevant targets for peptidyl-tyrosine autophosphorylation functional group were ErbB4 and EGFR, because they had more connections (each had 9 edges) with terms belonging to this group than the other targets. Besides, targets of LF triterpenoids also involved in response to epidermal growth factor, regulation of cyclin-dependent protein

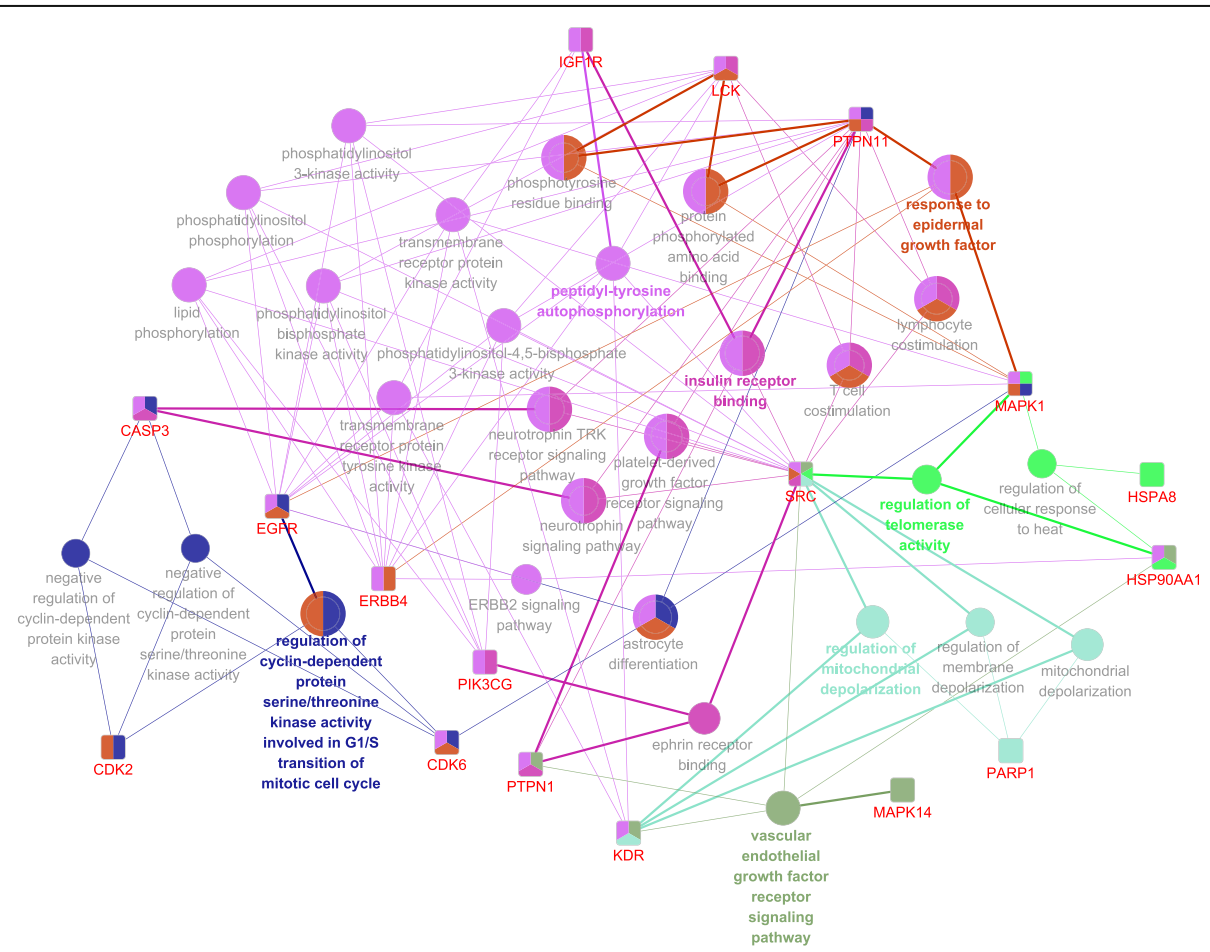

Fig. $7 \mathrm{GO}$ enrichment analysis of the identified targets of LF triterpenoids. Protein targets are represented by their gene names. Functional groups are colored and represented by their most significant term (leading term) based on the kappa statistics. The edge thickness shows kappascore relations between the targets and terms 


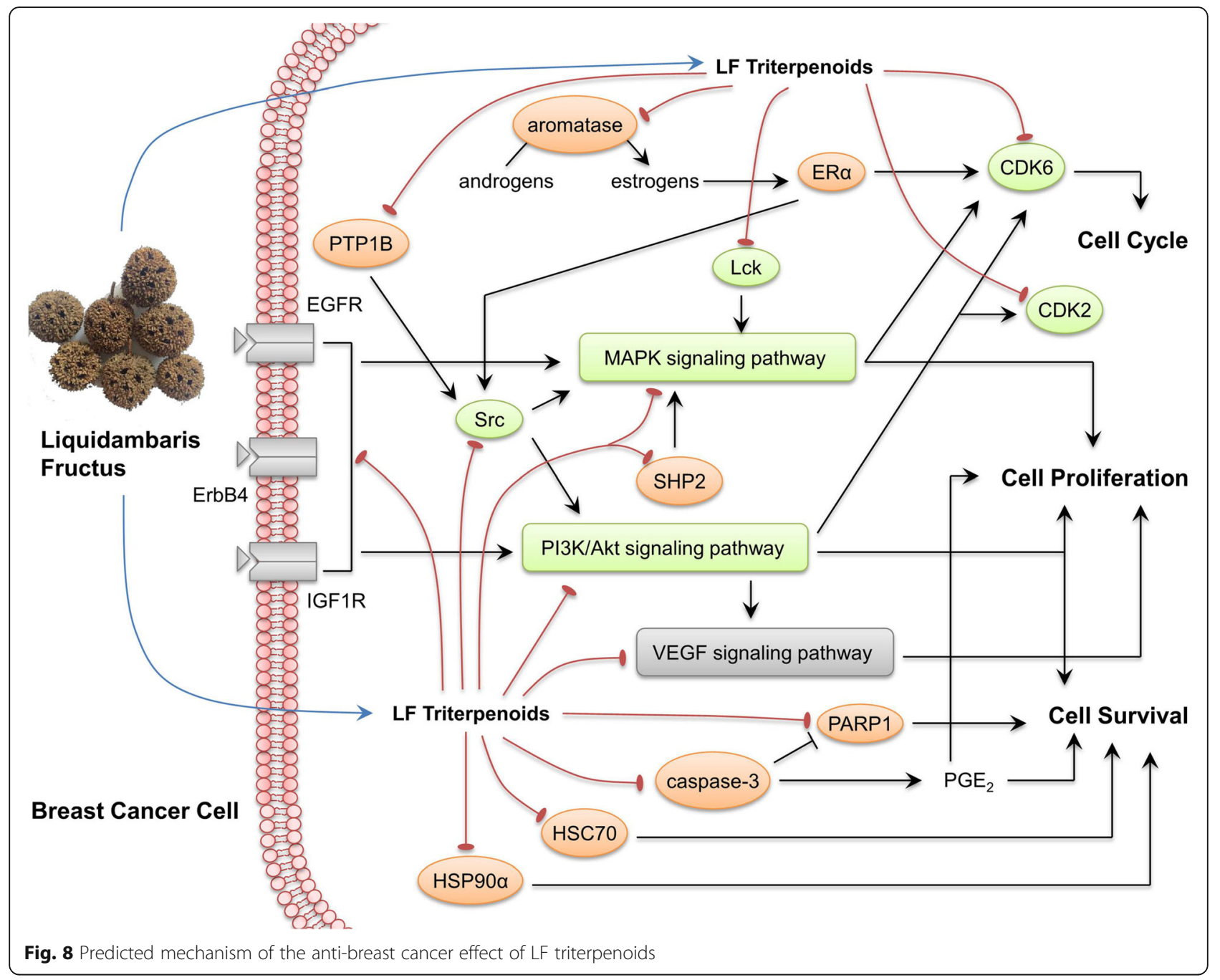

serine/threonine kinase activity, insulin receptor binding, regulation of mitochondrial depolarization, regulation of telomerase activity, vascular endothelial growth factor receptor signaling pathway, which were closed related to breast cancer progression.

According to the above result, we then analyzed signaling pathways concerned with the identified targets based on related studies $[45,46,50,51,55,57]$ and KEGG pathway database. By binding with the identified targets, LF triterpenoids could inhibit ErbB signaling pathway, MAPK signaling pathway, PI3K/Akt signaling pathway and VEGF signaling pathway, then inhibit cancer cells proliferation, and induce the cell cycle arrest and apoptosis (Fig. 8), which could explain the result of our previous research [6]. There have been studies showing that betulonic acid and other LF triterpenoids could induce cancer cell apoptosis and cell cycle arrest via inhibiting PI3K/Akt pathway [65-67], which could also support the predicted mechanism.

\section{Discussion}

According to the concept of polypharmacology, for complex diseases like cancers, inhibition of single target often induces chemo-resistance and lead to therapy failure [68-70]. In previous study we found the anti-breast cancer effect of betulonic acid [6], and this study revealed that LF triterpenoids might exert anti-breast cancer effect by directly inhibit multiple protein targets and signaling pathways, especially ErbB4 and EGFR and related pathways. It is worth noting that many of these targets were investigated or potential therapeutic targets of triplenegative, basal-like or advanced stage breast cancers, and patients with these types of breast cancer have rapid progression, high mortality rates, and high risk of recurrence and metastasis [59, 71]. Therefore the multi-targeted activity of LF triterpenoids revealed in this study could bring some inspirations in breast cancer treatment (Additional file 8). 
In addition, this study left an extra hint about the traditional applications of LF: as a high binding affinity target of LF triterpenoids, ErbB4 activity is essential for mammary gland development and the initiation of lactation [72], which meant that LF might aggravate rather than alleviate hypogalactia, contradicted with the description in Chinese Pharmacopoeia. Actually in early literature that involved LF, such as Bencao Gangmu Shiyi (1765 AD), no record showed that LF could promote lactation. Therefore this usage probably was an extension of its original efficacy because hypogalactia is considered a symptom caused by blocking of meridians. However, this extended usage need more evidence and this study gave a negative conclusion (Additional file 8).

Compared to synthetic drugs, Traditional Chinese Medicine is generally considered to have better safety. Although LF has been used for more than 250 years and no obvious adverse effects were reported, based on the result of the present study, there are still some precautions should be noted. Because ErbB4 play essential roles in the development of cardiac muscle and central nervous system during pregnancy [73], LF triterpenoids might have adverse effect on fetal development by inhibiting the activity of ErbB4. Besides, because Lck activation could initiate $\mathrm{T}$ cell antigen receptor signaling, and is a critical step in immune response [74], therefore LF triterpenoids probably could cause immune suppression by inhibiting Lck, and should be used very carefully on patients with immunodeficiency.

\section{Conclusion}

To further investigate the chemical ingredients of LF, 13 triterpenoids were identified and 6 of them were the first time isolated from LF. Using network pharmacologybased analysis in combination with molecular docking method, 18 protein targets, ErbB4, EGFR, CDK2, CDK6, p38 MAPK, ERK2, Lck, Src, IGF1R, PI3K $\gamma$, VEGFR2, aromatase, PTP1B, SHP2, caspase-3, PARP-1, HSP90 $\alpha$ and HSC70, were identified and by binding with these targets, LF triterpenoids could inhibit ErbB signaling pathway, MAPK signaling pathway, PI3K/Akt signaling pathway and VEGF signaling pathway, then inhibit breast cancer cells proliferation, and induce the cell cycle arrest and apoptosis. GO enrichment analysis indicated that ErbB4 and EGFR and related pathways might play more important roles during the process.

On the other hand, this study also revealed that LF triterpenoids could inhibit the activity of ErbB4 and accordingly suppressed rather than promoted lactation. Therefore the traditional applications of LF on hypogalactia should be reassessed systematically. Besides, this study also indicated that LF must be used very cautiously to treat women during pregnancy or patients with immunodeficiency, because LF triterpenoids might cause embryo toxicity and immune suppression by inhibiting the activity of ErbB4 and Lck.

\section{Supplementary Information}

The online version contains supplementary material available at https://doi. org/10.1186/s12906-020-03143-8.

Additional file 1. Separation process of the chemical compounds in LF. Additional file 2. Protein crystal structures and reference ligands used in the molecular docking experiment.

Additional file 3. The NMR spectrum of LF03, LF04, LF05, LF08, LF09 and LF10.

Additional file 4. Predicted targets of LF triterpenoids and therapeutic targets of breast cancer.

Additional file 5. Molecular docking results of LF triterpenoids. Additional file 6. Protein families that the molecular docking targets belonged to.

Additional file 7. Functionally grouped network view of the GO enrichment analysis result.

Additional file 8. The framework and research strategy of the article.

\section{Abbreviations}

AR: Androgen receptor; CDKs: Cyclin-dependent kinases; CMGC: The combination of CDKs; MAPKs: GSKs and CLKs; DFG: Asp-Phe-Gly; EGFR: Epidermal growth factor receptor; ERa: Estrogen receptor a; ERK2: Extracellular signal-regulated kinase 2; HPGDS: Hematopoietic prostaglandin D synthase; K/E/D/D: Lys/Glu/Asp/Asp; LBD: Ligand-binding domain; Lck: Lymphocyte cell-specific protein-tyrosine kinase; MAPK: Mitogen-activated protein kinase; PTP: Protein tyrosine phosphatases; SHP2: Src-homology 2 domain-containing phosphatase 2; TCPTP: T-cell protein tyrosine phosphatase

\section{Acknowledgements}

Not applicable.

Authors' contributions

DFZ and PQ conceived the idea of this article and supervised the research. $P Q, X T M$ and BS performed the research. PQ analyzed the data. PQ and LG wrote the manuscript. All authors read and approved the final manuscript.

\section{Funding}

This work was supported by the National Natural Science Foundation of China (grant number 81703756) and the Natural Science Foundation of Liaoning Province (grant number 20170541028).

Availability of data and materials

The datasets used and analyzed during the current study are available from the corresponding author on reasonable request.

Ethics approval and consent to participate

Not applicable.

Consent for publication

Not applicable.

Competing interests

The authors declare that they have no competing interests.

Received: 6 July 2020 Accepted: 31 October 2020

Published online: 27 November 2020

References

1. Chinese Pharmacopoeia Commission. Pharmacopoeia of the People's Republic of China, vol. I. Beijing: China Medical Science and Technology Press; 2015. 
2. Li Y, Gong X, Ding X. Research on the law of Chinese medicine in the treatment of early lactation acute mastitis. Chin J Ethnomed Ethnopharm. 2019;28:8-10,16

3. Xu J, Wang F, Li Z, Chen J. Randomized parallel control study of Chupixiaoyi granule combined drug lavage treatment on nipple discharge mammary duct ectasia. J Pract Tradit Chin Intern Med. 2017;31:70-3.

4. Du X. The flat by Sanjie powder in the treatment of breast cystic hyperplasia randomized parallel controlled study. J Pract Tradit Chin Intern Med. 2013;27:12-3.

5. Bray F, Ferlay J, Soerjomataram I, Siegel RL, Torre LA, Jemal A. Global cancer statistics 2018: GLOBOCAN estimates of incidence and mortality worldwide for 36 cancers in 185 countries. CA Cancer J Clin. 2018;68:394-424.

6. Mu XT, Qian P, Jiang LL, Wang Y, Jin X, Zhang DF. Effect of betulonic acid on proliferation of human breast cancer MCF-7 cells and human cervical cancer C-33A cells. Pract Pharm Clin Remedies. 2017:20:254-7.

7. Lai Z, Dong Y. Studies on the chemical constituents of Lu Lu Tong (1) structure determination of a novel pentacyclic triterpene. Acta Sci Nat Univ Sunyatseni. 1996;35:64-9.

8. Lai Z, Dong Y. Studies on the chemical constituents of Lu Lu Tong. (2). Acta Sci Nat Univ Sunyatseni. 1996;35:40-4.

9. Sun Y. Sun Y. Structure elucidation of liquidambaric lactone. Acta Pharm Sin. 1996:31:437-40.

10. Li C, Sun Y, Sun Y. A new triterpene from the fruits of Liquidambar formosana Hance-Lulutong. J Chin Pharm Sci. 2002;11:1-4.

11. Dat NT, Lee IS, Cai XF, Shen G, Kim YH. Oleanane triterpenoids with inhibitory activity against NFAT transcription factor from Liquidambar formosana. Biol Pharm Bull. 2004;27:426-8.

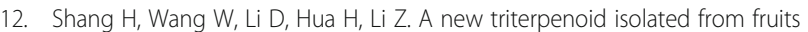
of Liquidambaris Fructus. Chin Tradit Herb Drugs. 2014;45:1207-10.

13. Wang X, Shen Y, Wang S, Li S, Zhang W, Liu X, et al. PharmMapper 2017 update: a web server for potential drug target identification with a comprehensive target pharmacophore database. Nucleic Acids Res. 2017:45:W356-60.

14. Ideker T, Sharan R. Protein networks in disease. Genome Res. 2008;18:644-52.

15. Bader GD, Hogue CW. An automated method for finding molecular complexes in large protein interaction networks. BMC Bioinformatics. 2003;4:2

16. Gavin AC, Bösche M, Krause R, Grandi P, Marzioch M, Bauer A, et al. Functional organization of the yeast proteome by systematic analysis of protein complexes. Nature. 2002;415:141-7.

17. Tong AHY, Drees B, Nardelli G, Bader GD, Brannetti B, Castagnoli L, et al. A combined experimental and computational strategy to define protein interaction networks for peptide recognition modules. Science (80- ). 2002; 295:321-4.

18. Torres PHM, Sodero ACR, Jofily P, Silva-Jr FP. Key topics in molecular docking for drug design. Int J Mol Sci. 2019;20:1-29.

19. Irungu BN, Orwa JA, Gruhnojic A, Fitzpatrick PA, Landberg G, Kimani F, et al Constituents of the roots and leaves of Ekebergia capensis and their potential antiplasmodial and cytotoxic activities. Molecules. 2014;19:14235-46.

20. Liu C, Xu JF, He QM, Yu QS. Chemical components of the Liquidambar formosana H. Resin Youji Huaxue. 1991;11:508-10.

21. Mahato SB, Kundu AP. 13C NMR spectra of pentacyclic triterpenoids-a compilation and some salient features. Phytochemistry. 1994;37:1517-75.

22. Peng C, Bodenhausen G, Qiu S, Fong HHS, Farnsworth NR, Yuan S, et al. Computer-assisted structure elucidation: application of CISOC-SES to the resonance assignment and structure generation of betulinic acid. Magn Reson Chem. 1998;36:267-78.

23. Cheng F, Li W, Zhou Y, Shen J, Wu Z, Liu G, et al. AdmetSAR: a comprehensive source and free tool for assessment of chemical ADMET properties. J Chem Inf Model. 2012;52:3099-105.

24. Li YH, Yu CY, Li XX, Zhang P, Tang J, Yang Q, et al. Therapeutic target database update 2018: enriched resource for facilitating bench-to-clinic research of targeted therapeutics. Nucleic Acids Res. 2018;46:D1121-7.

25. The UniProt Consortium. UniProt: the universal protein knowledgebase. Nucleic Acids Res. 2017;45:D158-69. https://doi.org/10.1093/nar/gkw1099.

26. Szklarczyk D, Morris JH, Cook H, Kuhn M, Wyder S, Simonovic M, et al. The STRING database in 2017: quality-controlled protein-protein association networks, made broadly accessible. Nucleic Acids Res. 2017:45:D362-8. https://doi.org/10.1093/nar/gkw937

27. Shannon P, Markiel A, Ozier O, Baliga NS, Wang JT, Ramage D, et al. Cytoscape: a software environment for integrated models of biomolecular interaction networks. Genome Res. 2003;13:2498-504. https://doi.org/10. 1101/gr.1239303.
28. Berman HM, Westbrook J, Feng Z, Gilliland G, Bhat TN, Weissig H, et al. The protein data Bank. Nucleic Acids Res. 2000;28:235-42. https://doi.org/10. 1093/nar/28.1.235

29. Bindea G, Mlecnik B, Hackl H, Charoentong P, Tosolini M, Kirilovsky A, et al. ClueGO: a Cytoscape plug-in to decipher functionally grouped gene ontology and pathway annotation networks. Bioinformatics. 2009;25:1091-3. https://doi.org/10.1093/bioinformatics/btp101.

30. Bindea G, Galon J, Mlecnik B. CluePedia Cytoscape plugin: pathway insights using integrated experimental and in silico data. Bioinformatics. 2013;29: 661-3. https://doi.org/10.1093/bioinformatics/btt019.

31. Varjosalo M, Keskitalo S, VanDrogen A, Nurkkala H, Vichalkovski A, Aebersold $\mathrm{R}$, et al. The protein interaction landscape of the human CMGC kinase group. Cell Rep. 2013;3:1306-20. https://doi.org/10.1016/j.celrep.2013.03.027.

32. Butti R, Das S, Gunasekaran VP, Yadav AS, Kumar D, Kundu GC. Receptor tyrosine kinases (RTKs) in breast cancer: signaling, therapeutic implications and challenges. Mol Cancer. 2018;17:1-18.

33. Hubbard SR, Till JH. Protein tyrosine kinase structure and function. Annu Rev Biochem. 2000;69:373-98. https://doi.org/10.1146/annurev.biochem.69.1.373.

34. Lodge AJ, Anderson JJ, Gullick WJ, Haugk B, Leonard RCF, Angus B. Type 1 growth factor receptor expression in node positive breast cancer: adverse prognostic significance of c-erbB-4. J Clin Pathol. 2003;56:300-4.

35. Kim JY, Jung HH, Do IG, Bae SY, Lee SK, Kim SW, et al. Prognostic value of ERBB4 expression in patients with triple negative breast cancer. BMC Cancer. 2016;16:1-12.

36. Roskoski R. A historical overview of protein kinases and their targeted small molecule inhibitors. Pharmacol Res. 2015;100:1-23. https://doi.org/10.1016/j. phrs.2015.07.010.

37. Roskoski R. Small molecule inhibitors targeting the EGFR/ErbB family of protein-tyrosine kinases in human cancers. Pharmacol Res. November 2018; 2019(139):395-411. https://doi.org/10.1016/j.phrs.2018.11.014.

38. Herrera-Abreu MT, Palafox M, Asghar U, Rivas MA, Cutts RJ, Garcia-Murillas I, et al. Early adaptation and acquired resistance to CDK4/6 inhibition in estrogen receptor-positive breast cancer. Cancer Res. 2016;76:2301-13.

39. Asghar US, Barr AR, Cutts R, Beaney M, Babina I, Sampath D, et al. Single-cell dynamics determines response to CDK4/6 inhibition in triple-negative breast cancer. Clin Cancer Res. 2017:23:5561-72.

40. Roskoski R. Cyclin-dependent protein serine/threonine kinase inhibitors as anticancer drugs. Pharmacol Res. 2019;139:471-88. https://doi.org/10.1016/j. phrs.2018.11.035.

41. Gee JMW, Robertson JFR, Ellis IO, Nicholson RI. Phosphorylation of ERK1/2 mitogen-activated protein kinase is associated with poor response to antihormonal therapy and decreased patient survival in clinical breast cancer. Int J Cancer. 2001;95:247-54. https://doi.org/10.1002/10970215(20010720)95:4<247::AID-IJC1042>3.0.CO;2-S.

42. Yeh YT, Hou MF, Chung YF, Chen YJ, Yang SF, Chen DC, et al. Decreased expression of phosphorylated JNK in breast infiltrating ductal carcinoma is associated with a better overall survival. Int J Cancer. 2006;118:2678-84.

43. Esteva FJ, Sahin AA, Smith TL, Yang Y, Pusztai L, Nahta R, et al. Prognostic significance of phosphorylated P38 mitogen-activated protein kinase and HER-2 expression in lymph node-positive breast carcinoma. Cancer. 2004; 100:499-506.

44. Wu T, Wang $X, L i$ J, Song $X$, Wang $Y$, Wang $Y$, et al. Identification of personalized chemoresistance genes in subtypes of basal-like breast cancer based on functional differences using pathway analysis. PLoS One. 2015:10:1-18.

45. Chakraborty G, Rangaswami H, Jain S, Kundu GC. Hypoxia regulates crosstalk between Syk and Lck leading to breast cancer progression and angiogenesis. J Biol Chem. 2006;281:11322-31.

46. Sibilski C, Mueller T, Kollipara L, Zahedi RP, Rapp UR, Rudel T, et al. Tyr728 in the kinase domain of the murine kinase suppressor of RAS 1 regulates binding and activation of the mitogen-activated protein kinase kinase. J Biol Chem. 2013:288:35237-52.

47. Narayanan R, Dalton JT. Androgen receptor: a complex therapeutic target for breast cancer. Cancers (Basel). 2016:8:1-17.

48. Yousefnia S, Momenzadeh S, Seyed Forootan F, Ghaedi K, Nasr Esfahani MH. The influence of peroxisome proliferator-activated receptor $\gamma$ (PPARY) ligands on cancer cell tumorigenicity. Gene. 2018;649:14-22. https://doi.org/ 10.1016/j.gene.2018.01.018.

49. Ghosh D, Griswold J, Erman M, Pangborn W. Structural basis for androgen specificity and oestrogen synthesis in human aromatase. Nature. 2009:457: 219-23. https://doi.org/10.1038/nature07614. 
50. Julien SG, Dubé N, Read M, Penney J, Paquet M, Han Y, et al. Protein tyrosine phosphatase 1B deficiency or inhibition delays ErbB2-induced mammary tumorigenesis and protects from lung metastasis. Nat Genet. 2007:39:338-46.

51. Yu M, Liu Z, Liu Y, Zhou X, Sun F, Liu Y, et al. PTP1B markedly promotes breast cancer progression and is regulated by miR-193a-3p. FEBS J. 2019; 286:1136-53.

52. Zhang Y, Du Y. The development of protein tyrosine phosphatase1B inhibitors defined by binding sites in crystalline complexes. Future Med Chem. 2018;10:2345-67.

53. Li XQ, Wang $\sqcup$, Shi DY. The design strategy of selective PTP1B inhibitors over TCPTP. Bioorg Med Chem. 2016;24:3343-52. https://doi.org/10.1016/j. bmc.2016.06.035.

54. Butterworth S, Overduin M, Barr AJ. Targeting protein tyrosine phosphatase SHP2 for therapeutic intervention. Future Med Chem. 2014;6:1423-37. https://doi.org/10.4155/fmc.14.88.

55. Aceto N, Sausgruber N, Brinkhaus H, Gaidatzis D, Martiny-Baron G, Mazzarol G, et al. Tyrosine phosphatase SHP2 promotes breast cancer progression and maintains tumor-initiating cells via activation of key transcription factors and a positive feedback signaling loop. Nat Med. 2012;18:529-37.

56. Zhang X, He Y, Liu S, Yu Z, Jiang Z-X, Yang Z, et al. Salicylic acid based small molecule inhibitor for the oncogenic Src homology-2 domain containing protein tyrosine phosphatase-2 (SHP2). J Med Chem. 2010;53:2482-93. https://doi.org/10.1021/jm901645u.

57. Huang Q, Li F, Liu X, Li W, Shi W, Liu F, et al. Caspase 3-mediated repopulation of cancer cels after radiotherapy. Nat Med. 2012;17:860-6.

58. Gibson BA, Kraus WL. New insights into the molecular and cellular functions of poly (ADP-ribose) and PARPs. Nat Rev Mol Cell Biol. 2012;13:411-24.

59. Lee A, Djamgoz MBA. Triple negative breast cancer: emerging therapeutic modalities and novel combination therapies. Cancer Treat Rev. 2018;62:11022. https://doi.org/10.1016/j.ctrv.2017.11.003.

60. Steffen JD, Brody JR, Armen RS, Pascal JM. Structural implications for selective targeting of PARPs. Front Oncol. 2013;3(December):301.

61. Jego G, Hazoumé A, Seigneuric R, Garrido C. Targeting heat shock proteins in cancer. Cancer Lett. 2013;332:275-85. https://doi.org/10.1016/j.canlet.2010. 10.014 .

62. Vazquez A, Bond EE, Levine AJ, Bond GL. The genetics of the p53 pathway, apoptosis and cancer therapy. Nat Rev Drug Discov. 2008;7:979-87.

63. Park JM, Kanaoka Y, Eguchi N, Aritake K, Grujic S, Materi AM, et al. Hematopoietic prostaglandin D synthase suppresses intestinal adenomas in Apc min/+ mice. Cancer Res. 2007;67:881-9. https://doi.org/10.1158/00085472.CAN-05-3767.

64. Fukuoka T, Yashiro M, Kinoshita H, Morisaki T, Hasegawa T, Hirakawa T, et al. Prostaglandin $\mathrm{d}$ synthase is a potential novel therapeutic agent for the treatment of gastric carcinomas expressing PPARy. Int J Cancer. 2015;137: $1235-44$.

65. Zhang XJ, Han L, Ji YB, Fang GZ. Studies of betulonic acid on cell cycle and related protein expression on mice of bearing H22 tumor cells. China J Chin Mater Medica. 2008:33:1739-43.

66. Leong KH, Mahdzir MA, Din MFM, Awang K, Tanaka Y, Kulkeaw K, et al. Induction of intrinsic apoptosis in leukaemia stem cells and in vivo zebrafish model by betulonic acid isolated from Walsura pinnata Hassk (Meliaceae). Phytomedicine. 2017;26:11-21. https://doi.org/10.1016/j.phymed.2016.12.018.

67. Zhang H, Kang Y, Li N, Wang H, Bao Y, Li Y, et al. Triterpenoids from Liquidambar Fructus induced cell apoptosis via a PI3K-AKT related signal pathway in SMMC7721 cancer cells. Phytochemistry. 2020;171:112228. https://doi.org/10.1016/j.phytochem.2019.112228.

68. Knight ZA, Lin H, Shokat KM. Targeting the cancer kinome through polypharmacology. Nat Rev Cancer. 2010;10:130-7.

69. Huang S, Kauffman S. How to escape the cancer attractor: rationale and limitations of multi-target drugs. Semin Cancer Biol. 2013;23:270-8. https:// doi.org/10.1016/j.semcancer.2013.06.003.

70. Raghavendra NM, Pingili D, Kadasi S, Mettu A, Prasad SVUM. Dual or multitargeting inhibitors: the next generation anticancer agents. Eur J Med Chem. 2018;143:1277-300. https://doi.org/10.1016/j.ejmech.2017.10.021.

71. Dent R, Trudeau M, Pritchard Kl, Hanna WM, Kahn HK, Sawka CA, et al. Triple-negative breast cancer: clinical features and patterns of recurrence. Clin Cancer Res. 2007;13:4429-34.

72. Jones FE. HER4 intracellular domain (4ICD) activity in the developing mammary gland and breast cancer. J Mammary Gland Biol Neoplasia. 2008; 13:247-58.
73. Gassmann M, Casagranda F, Orioli D, Simon H, Lai C, Klein R, et al. Aberrant neural and cardiac development in mice lacking the ErbB4 neuregulin receptor. Nature. 1995;378:390-4. https://doi.org/10.1038/378390a0.

74. Meyn M III, Smithgall T. Small molecule inhibitors of Lck: the search for specificity within a kinase family. Mini Rev Med Chem. 2008;8:628-37.

75. Poehland BL, Carté BK, Francis TA, Hyland LJ, Allaudeen HS, Troupe N. In vitro antiviral activity of dammar resin triterpenoids. J Nat Prod. 1987;50: 706-13. https://doi.org/10.1021/np50052a022.

76. Shirane N, Hashimoto Y, Ueda K, Takenaka H, Katoh K. Ring-a cleavage of 3oxo-olean-12-en-28-oic acid by the fungus Chaetomium longirostre. Phytochemistry. 1996;43:99-104.

\section{Publisher's Note}

Springer Nature remains neutral with regard to jurisdictional claims in published maps and institutional affiliations.
Ready to submit your research? Choose BMC and benefit from:

- fast, convenient online submission

- thorough peer review by experienced researchers in your field

- rapid publication on acceptance

- support for research data, including large and complex data types

- gold Open Access which fosters wider collaboration and increased citations

- maximum visibility for your research: over $100 \mathrm{M}$ website views per year

At BMC, research is always in progress.

Learn more biomedcentral.com/submissions 